OPEN ACCESS

Edited by:

Maria João Fraqueza,

University of Lisbon, Portugal

Reviewed by:

Jozsef Soki,

University of Szeged, Hungary

Xiaoqing $\mathrm{Hu}$,

Jiangnan University, China

Maria Miragaia,

Instituto de Tecnologia Química e

Biológica (ITQB-NOVA),

Portugal

*Correspondence: Sabine Leroy

sabine.leroy@inra.fr

Specialty section:

This article was submitted to

Food Microbiology,

a section of the journal

Frontiers in Microbiology

Received: 13 August 2018

Accepted: 13 February 2019

Published: 06 March 2019

Citation:

Leroy S, Christieans $S$ and Talon $R$

(2019) Tetracycline Gene Transfer in

Staphylococcus xylosus in situ During

Sausage Fermentation.

Front. Microbiol. 10:392.

doi: 10.3389/fmicb.2019.00392

\section{Tetracycline Gene Transfer in Staphylococcus xylosus in situ During Sausage Fermentation}

\author{
Sabine Leroy ${ }^{1 *}$, Souad Christieans ${ }^{2}$ and Régine Talon ${ }^{1}$ \\ ${ }^{1}$ Université Clermont Auvergne, INRA, MEDiS, Clermont-Ferrand, France, ${ }^{2} A D I V, Z A C$ des Gravanches, \\ Clermont-Ferrand, France
}

The presence of determinants of resistance to antibiotics can constitute a possible safety hazard in coagulase-negative staphylococci (CNS), which are widely present in food of animal origin. Among CNS, S. xylosus is a species frequently isolated from fermented meat products. Resistance to tetracycline was found to be one of the most distributed resistances occurring in S. xylosus strains isolated from fermented sausages. We evaluated the transfer of tetracycline resistance in vitro and in situ between S. xylosus strains. We selected three strains isolated from dry fermented sausages, resistant to tetracycline but not to minocycline, their resistance occurring by a mechanism of active efflux encoded by the tetK gene. Only one strain was able to transfer its tetracycline resistance to a recipient strain initially susceptible and plasmid-free using a filter mating procedure. Transfer of tetracycline resistance was observed at very low frequencies of $3.4 \times 10^{-9}$ per recipient. To further investigate the transferability of this tetracycline resistance, the donor and recipient strains were tested in pilot-scale fermented sausage production. This transfer was possible but at a low rate, $1.4 \times 10^{-7}$, and only under conditions of a high inoculation level of $10^{8} \mathrm{CFU} / \mathrm{g}$ of meat. The tetK gene is located on a small mobilizable plasmid close to Staphylococcus aureus PT181 plasmid. In conclusion, the transfer of tetracycline resistance between strains of $S$. xylosus is possible, but at a really low frequency in vitro and in situ in fermented sausages. Even if this represents a very moderate risk, it should be taken into account as required by the European approach of Qualified Presumption of Safety (QPS) and AFSSA safety recommendations, advising that strains used as starter cultures should not carry any transferable antibiotic resistance.

Keywords: S. xylosus, antibiotic resistance, tetracycline, transfer, sausage

\section{INTRODUCTION}

Coagulase-negative staphylococci (CNS) are widely present in microbial ecosystems of fermented foods, in particular of animal origin (Coton et al., 2010; Leroy et al., 2010; Greppi et al., 2015; Sánchez Mainar et al., 2017). Among CNS, S. xylosus is a ubiquitous gram-positive bacterium naturally present in these foods and commonly used as starter culture for dry fermented sausages (Coton et al., 2010; Leroy et al., 2010; Ratsimba et al., 2017). It is shown to occur in numbers of $10^{6}-10^{7} \mathrm{CFU} / \mathrm{g}$ in naturally fermented meat products and in inoculated ones. 
Tetracycline is a broad-spectrum antibiotic that has been widely used since the 1940s (Chopra and Roberts, 2001). As a consequence of its use in animal husbandry, antibioticresistant pathogenic and commensal bacteria have been detected in various animal products including fermented foods derived from meat and milk (Devirgiliis et al., 2011; Li et al., 2016; Chon et al., 2016; Anisimova and Yarullina, 2018; Ed-Dra et al., 2018; Lüdin et al., 2018; Wu et al., 2018). Among these bacteria, CNS can be a reservoir of antibiotic-resistant bacteria (Malik et al., 2005; Even et al., 2010; Talon and Leroy, 2011). In several studies, resistance to tetracycline was found to be the most distributed resistance occurring in $S$. xylosus strains isolated from the food chain. Thus, the 12 strains of $S$. xylosus collected from the production chain of swine meat commodities (feces, feed, meat, sausage) were resistant to tetracycline (Simeoni et al., 2008). This high prevalence of resistance was also true for $S$. xylosus isolated from domestic animals (oropharyngeal, rectal samples) (Bhargava and Zhang, 2012). Resistance to tetracycline ranging from 12 to $38 \%$ was recorded for S. xylosus associated with fermented sausages, cheeses, or meat starter cultures (Mauriello et al., 2000; Kastner et al., 2006; Martín et al., 2006; Resch et al., 2008; Even et al., 2010; Marty et al., 2012; ChajęckaWierzchowska et al., 2015).

The tetracycline resistome represented by more than 40 determinants falls in three categories, ribosomal protection proteins, active efflux pumps, and enzymatic inactivation (Thaker et al., 2010; van Hoek et al., 2011). In staphylococci resistance can occur by ribosome protection encoded by tet $M$, tet $O$, tet $S$, and tet $W$ genes, by efflux pumps encoded by tet $K$, tet $L$, tet 38 , and tet 42 genes, and by an unknown mechanism encoded by tet $U$ (Roberts, 1996; Schwarz et al., 1998; Malik et al., 2005; van Hoek et al., 2011). The gene tet $M$ was mostly identified in S. xylosus isolated from the skin of pigs (Schwarz and Noble, 1994), the production chain of swine meat commodities (Simeoni et al., 2008) and domestic animals (Bhargava and Zhang, 2012), but it was also found in ready-to-eat food of animal origin (Chajęcka-Wierzchowska et al., 2015). The conjugative transposon $\mathrm{Tn} 916$ is often associated with tetM (Chopra and Roberts, 2001; ChajęckaWierzchowska et al., 2015). However, tetK was found to be the dominant mechanism in S. xylosus (Kastner et al., 2006; Resch et al., 2008; Even et al., 2010; Marty et al., 2012). Gram-positive efflux genes are associated with small potentially transmissible plasmids (Schwarz and Noble, 1994; Chopra and Roberts, 2001).

The consumption of fermented foods such as fermented sausages with high levels of $S$. xylosus resulted in ingestion of high amounts of living bacteria. Antibiotic resistance determinants present in S. xylosus strains naturally and frequently present in fermented meat products lead to the question: Could these strains act as reservoirs for antibiotic resistance gene spreading in starter culture strains? Thus, the objective of this work was to study in vitro and in situ in fermented sausages the risk and frequency of intra-specific horizontal transfer of tetracycline resistance gene.

\section{MATERIALS AND METHODS}

\section{Bacterial Strains and Growth Conditions}

Four strains of $S$. xylosus were used. Three strains isolated from dry fermented sausages are resistant to tetracycline and sensitive to minocycline, their resistance occurring by a mechanism of active efflux encoded by the tet $K$ gene as determined by hybridization of a diagnostic microarray including 10 tet gene probes commonly found in Gram-positive bacteria, i.e., tet $A, \operatorname{tet} B$, tet $K$, tet $L$, tet $M$, tetP, tetS, tet $T$, tet $U$, and tet $W$ (Even et al., 2010). The C2a strain is derived from the type strain DSM20267 cured of its endogenous plasmid (Götz et al., 1983). This strain is sensitive to tetracycline and resistant to rifampicin. We selected a spontaneous fusidic acid-resistant mutant from the $\mathrm{C} 2 \mathrm{a}$ strain as a recipient strain.

The S. xylosus strains were cultured in Brain Heart Infusion (BHI, Difco) under aerobic conditions (1:10 volume to flask ratio, $150 \mathrm{rpm}$ ) or on $\mathrm{BHI}$ Agar (Difco) at $37^{\circ} \mathrm{C}$. The $\mathrm{BHI}$ medium, when required, was supplemented with antibiotics at the following concentrations: $10 \mu \mathrm{g} / \mathrm{ml}$ tetracycline (Tet), $25 \mu \mathrm{g} / \mathrm{ml} \mathrm{rifampicin} \mathrm{(Rif),} \mathrm{and/or} 25 \mu \mathrm{g} / \mathrm{ml}$ fusidic acid (Fus) (Sigma-Aldrich).

\section{Transfer in vitro}

Transfer experiments were performed by filter mating. The donor and recipient strains were cultivated separately overnight with the appropriate resistance selection to reach about $8 \times 10^{8} \mathrm{CFU} / \mathrm{ml}$. Cells were mixed in a donor/recipient ratio of $1: 3$ or $1: 10$. Typically, 350 or $100 \mu \mathrm{l}$ of donor and 700 or $900 \mu \mathrm{l}$ of recipient, respectively, were pelleted and suspended in $400 \mu \mathrm{l}$ of BHI and dropped onto $0.45 \mu \mathrm{m}$ cellulose nitrate membrane filters (Whatman). The filters were incubated on $\mathrm{BHI}$ agar plates for $18 \mathrm{~h}$ at $37^{\circ} \mathrm{C}$. After mating, cells were recovered from the filters by vortexing in $1 \mathrm{ml}$ of $\mathrm{BHI}$. Transconjugants were selected by plating serial dilutions of the mating suspension on BHI agar supplemented with Tet, Rif, and Fus. The plates were incubated for $48 \mathrm{~h}$ at $37^{\circ} \mathrm{C}$. After incubation, the resulting colonies were picked up and replicated on BHI containing Tet, Rif, and Fus. Likewise, donor and recipient strains were plated as control onto BHI agar containing Tet or Rif and Fus, respectively. The frequency of transfer was expressed as the number of conjugants per recipient. Presumptive transconjugants were confirmed by antibiotic disk diffusion, PCR-based detection of tetK gene, plasmid profiling, and PFGE typing as described below.

\section{Transfer in situ in Fermented Sausages}

Batter was prepared by grinding raw materials (lean pork $80 \%$, pork back fat 20\%) to obtain particles of $6 \mathrm{~mm}$ diameter and was seasoned with dextrose $(0.5 \%)$, salt $(2.6 \%)$, saltpeter $(0.03 \%)$, and pepper $(0.15 \%)$. It was inoculated with starter culture Lactobacillus sakei $10^{6} \mathrm{CFU} / \mathrm{g}$. The batter was then divided into two batches that were inoculated by $S$. xylosus strains XIV $10 \mathrm{~B} 1$ and C2a at about $10^{6} \mathrm{CFU} / \mathrm{g}$ each in batch 1 and $10^{8} \mathrm{CFU} / \mathrm{g}$ each in batch 2 . The mixtures were stuffed into 
natural casings. After stuffing, sausages were dipped into a Penicillium surface suspension and hung vertically in a temperature and humidity controlled incubator (ARCOS, France) to carry on the ripening process (fermentation and drying). The products were fermented at $22 / 24^{\circ} \mathrm{C}$ for 6 days $96-94 \%$ $\mathrm{RH}$ (relative humidity), then dried for 24 days at $13^{\circ} \mathrm{C} / 14^{\circ} \mathrm{C}$ and $80-82 \% \mathrm{RH}$.

Samples were taken at T0 (after inoculation and stuffing), T6 (end of fermentation stage), and T30 (end of drying). The $\mathrm{pH}$ of the samples was recorded using a $\mathrm{pH}$ meter MP230 (Mettler Toledo, Viroflay, France) with a pH probe (Inlab 427 penetration probe; Mettler Toledo). The water activity (aw) was measured with an aw-sprint TH500 (Novasina, Roucaire, France). Lactic acid bacteria (LAB) were enumerated on MRS agar (Oxoid) $\mathrm{pH} 5.7$ incubated in anaerobic conditions at $30^{\circ} \mathrm{C}$ for 72 h. Staphylococci were enumerated on Chapman (Oxoid) after incubation for $24-48 \mathrm{~h}$ at $37^{\circ} \mathrm{C}$. After counting, a replica-plating procedure was performed on BHI agar supplemented with appropriate antibiotics. Bacterial enumeration was also directly performed on BHI agar supplemented with (1) Rif and Fus, (2) Tet, or (3) Tet, Rif, and Fus. The plates were incubated for $24-48 \mathrm{~h}$ at $37^{\circ} \mathrm{C}$. Rapid identification of S. xylosus was performed by direct colony PCR using species-specific primers as described (Morot-Bizot et al., 2003; Corbière Morot-Bizot et al., 2004). Presumptive transconjugants were confirmed as described below.

\section{Disk Diffusion Method}

Antibiotic susceptibilities were evaluated by the disk diffusion method according to the guidelines of the CA-SFM (2017) with Mueller Hinton agar (Sigma-Aldrich). The following antimicrobial susceptibility test disks (Bio-Rad) were used: fusidic acid $(10 \mu \mathrm{g})$, minocycline $(30 \mu \mathrm{g})$, penicillin $\mathrm{G}(6 \mu \mathrm{g})$, rifampicin $(5 \mu \mathrm{g})$, and tetracycline $(30 \mu \mathrm{g})$. Inhibition zones were measured, and the susceptibility was determined as suggested by the CA-SFM standards.

\section{PCR Detection of tetK Gene}

Total DNA from S. xylosus was isolated by the method of Marmur (1961). Approximately $10 \mathrm{ng}$ of total DNA was used as a PCR template. The primers used for tet $K$ amplification were GTAGCGACAATAGGTAATAGT and GTAGTGACAATAAACCTCCTA (Strommenger et al., 2003). PCR was performed in a $50 \mu \mathrm{L}$ reaction mixture containing 5 pmol of each primer, $200 \mu \mathrm{M}$ of each dNTP, $1.5 \mathrm{mM}$ $\mathrm{MgCl}_{2}, 1 \times$ Taq DNA polymerase buffer, and $0.5 \mathrm{U}$ of Taq DNA polymerase (Promega). The amplification cycle was as follows: $3 \mathrm{~min}$ at $94^{\circ} \mathrm{C} ; 30$ cycles of $30 \mathrm{~s}$ at $94^{\circ} \mathrm{C}, 30 \mathrm{~s}$ at $55^{\circ} \mathrm{C}$, and $30 \mathrm{~s}$ at $72^{\circ} \mathrm{C}$; and a final extension of $4 \mathrm{~min}$ at $72^{\circ} \mathrm{C}$. The amplification products were analyzed on $2 \%$ agarose gel and visualized by ethidium bromide. PCR product of 360-bp was further checked by sequencing.

\section{Plasmid Profiling and Sequencing}

Plasmid DNA from S. xylosus was extracted using the QIAprep Miniprep Kit (Qiagen) after cell lysis with $16 \mu \mathrm{g} / \mathrm{ml}$ lysostaphin.
The plasmid content was verified on a $0.8 \%$ agarose gel and visualized by ethidium bromide or transferred onto positively charged nylon membranes (Hybond-N+, Amersham Biosciences). Southern blot hybridization was performed using the tetK PCR product (360 bp long) from S. xylosus XIV 10B1 as a probe. The PCR product was first purified with a Qiaquick PCR purification Kit (Qiagen) and labeled using the DIG-High Prime DNA Labeling Kit (Sigma-Aldrich). Pre-hybridization and hybridization were performed with DIG Easy Hyb solution (Sigma-Aldrich) at $42^{\circ} \mathrm{C}$. Washes were performed for $10 \mathrm{~min}$ at room temperature in $2 \mathrm{X}$ SSC, $0.1 \%$ sodium dodecyl sulfate (SDS), and for $30 \mathrm{~min}$ at $68^{\circ} \mathrm{C}$ in $0.1 \mathrm{X}$ SSC, $0.1 \%$ SDS. NBT-BCIP (Sigma-Aldrich) was used for the detection.

The plasmid sequences adjacent to the 360-bp tet $K$ fragment have been recovered by inverse PCR using inversely oriented primers, IP-AM1 AAAAGATAATCCGCCCATAACA and IP-AV1 TGCTTCTGGAATGAGTTTGCT. Approximately $1 \mathrm{ng}$ of plasmid content was used as a template. Inverse PCR was performed in a $50 \mu \mathrm{l}$ reaction mixture containing $5 \mathrm{pmol}$ of each primer, $200 \mu \mathrm{M}$ of each dNTP, $1 \times$ AccuTaq buffer, and $2.5 \mathrm{U}$ of AccuTaq LA DNA polymerase (Sigma-Aldrich). The amplification cycle was as follows: $5 \mathrm{~min}$ at $94^{\circ} \mathrm{C} ; 30$ cycles of $30 \mathrm{~s}$ at $94^{\circ} \mathrm{C}, 30 \mathrm{~s}$ at $55^{\circ} \mathrm{C}$, and $5 \mathrm{~min}$ at $68^{\circ} \mathrm{C}$; and a final extension of $10 \mathrm{~min}$ at $68^{\circ} \mathrm{C}$ for amplification of an expected product of about $5 \mathrm{~kb}$.

The amplification product was analyzed on $0.8 \%$ agarose gel and visualized by ethidium bromide. Finally, the inverse PCR product was gel-purified with extraction from agarose using the QIAquick Gel Extraction Kit (Qiagen) for primerwalking-strategy DNA sequencing. Sequences were assembled into a contig using CAP3 (Huang and Madan, 1999) and then analyzed using the NCBI BLAST suite of programs.

\section{PFGE Typing}

Genomic DNA of $S$. xylosus was prepared in agarose plugs as described previously (Morot-Bizot et al., 2003). The enzyme SmaI was used according to the manufacturer's instructions (Promega). Digested DNA was subjected to pulsed-field gel electrophoresis (PFGE) in 1\% agarose gels in $0.5 \times$ TBE buffer on a CHEF-DR III apparatus (Bio-Rad). Electrophoretic conditions were $50-100 \mathrm{~s}$ for $6 \mathrm{~h}$ and $10-30 \mathrm{~s}$ for $18 \mathrm{~h}$ at $14 \mathrm{C}$ at $6 \mathrm{~V} / \mathrm{cm}$ and an angle of $120^{\circ}$. Lambda DNA concatemers were used as molecular size markers (Promega). Gel was stained in ethidium bromide.

\section{Nucleotide Sequence Accession Number}

The GenBank accession number of the full-length sequence of plasmid pSX10B1 with annotations is MK433518.

\section{RESULTS}

\section{Transfer in vitro and in situ in Fermented Sausages}

The three S. xylosus strains resistant to tetracycline were used as donors, and the $\mathrm{C} 2 \mathrm{a}$ strain was used as recipient in filter 
mating experiments. The transfer of tetracycline resistance was only observed in the case of a donor/recipient ratio of 1:10 and the XIV $10 \mathrm{~B} 1$ strain as a donor. The transfer occurred at a low frequency of $3.4 \times 10^{-9}$ per recipient, and two presumptive transconjugants (TC1 and TC2) were isolated.

To study the potential transfer of tetracycline resistance of the XIV 10B1 strain in situ in meat matrix, fermented sausages were made on a pilot scale mimicking the industrial process. Two batches were prepared with the same raw materials and inoculated with $L$. sakei as starter (sensitive to tetracycline), but with two different levels of S. xylosus (donor and recipient, ratio 1:1): one at approximately $6 \mathrm{log} \mathrm{CFU} / \mathrm{g}$ (batch E1) and the other at $8 \mathrm{log}$ CFU/g (batch E2) (Table 1). The ratio 1:1 has been chosen because plasmid transfers were observed for Lactobacillus curvatus during sausage fermentation (Vogel et al., 1992). The fermented sausages were analyzed over a ripening period of 30 days.

A growth of approximately two logs was recorded for lactic acid bacteria in both batches (Table 1). They grew during the fermentation and ripening steps. A drop in $\mathrm{pH}$ was noted during the fermentation phase followed by an increase during the ripening step in the two batches. Finally, water activity decreased during ripening in both batches (Table 1).

Enumeration of staphylococci on Chapman medium is shown in Table 1. The staphylococcal count remained close to their level of inoculation throughout the process in both batches. All randomly selected colonies were identified as S. xylosus. No transconjugants were isolated by replica plating of colonies grown on Chapman agar.

In batch E1, the donor strain grew during the fermentation step and then remained at the same level, while the recipient strain decreased slightly during the process (Table 1). In the condition of batch 1 , no presumptive transconjugant was isolated on medium supplemented with Tet, Rif, and Fus (Table 1).

In batch E2, the donor and recipient strains remained at their level of inoculation up to the fermentation, and a slight decrease was noted at 30 days of ripening. Presumptive transconjugants were isolated on medium supplemented with
Tet, Rif, and Fus after 6 days of fermentation (E2-1, E2-2, and E2-3) and after 30 days of ripening (E2-4). These presumptive transconjugants were only detected on plates inoculated from the $10^{-1}$ sample dilution. The frequency of the transfer can be estimated at a rate of $1.4 \times 10^{-7}$ per recipient after 6 days of fermentation.

\section{Confirmation of Transconjugants}

The six colonies of presumptive transconjugants were picked from selective plates and were characterized to determine if these isolates were "true" transconjugants and not mutants of donor or recipient.

Antibiotic susceptibility for presumptive transconjugants and donor and recipient strains was determined by a disk diffusion test (Table 2). All transconjugants were resistant to tetracycline and sensitive to minocycline, like the donor strain. Their resistance to rifampicin and fusidic acid was identical to those of the chromosomally resistant recipient strain. The resistance to penicillin $\mathrm{G}$ of the donor strain had not been transferred. Note that the transferred tetracycline resistance is stably maintained in all transconjugants in the absence of selective pressure.

We have shown that PCR amplification was successful in detecting tet $K$ in all presumptive transconjugants as in the XIV 10B1 donor strain (Figure 1). The sequencing of the XIV 10B1 360 bp-PCR product confirmed that the PCR was specific.

When comparing plasmid carriage of presumptive transconjugants with the donor strain, we have shown that all transconjugants harbored a small plasmid $(<5 \mathrm{~kb})$ of similar size to that of the donor strain (Figure 2A). This small transmissible plasmid hybridized with the tetK probe (Figure 2B). We have observed in the four transconjugants obtained in situ the additional transfer of a smaller plasmid (Figure 2B). The complete nucleotide sequence of the plasmid carrying tet $K$ was obtained. Plasmid pSX10B1 is 4,498 bp long with $30.1 \% \mathrm{G}+\mathrm{C}$ content. The sequence encodes three open reading frames, which correspond to a replication initiation protein, a tetracycline resistance protein

TABLE 1 | Microbial and physico-chemical-characteristics of the fermented sausages over 30 days of ripening.

\begin{tabular}{|c|c|c|c|c|}
\hline Selective media & Days & TO & T6 & T30 \\
\hline \multirow[t]{2}{*}{ Batch E1 } & $\mathrm{pH}$ & $5.80 \pm 0.08$ & $5.20 \pm 0.06$ & $5.55 \pm 0.12$ \\
\hline & Aw & $0.97 \pm 0.01$ & $0.95 \pm 0.02$ & $0.91 \pm 0.01$ \\
\hline MRS & Lactic acid bacteria & $6.45 \pm 0.26$ & $7.68 \pm 0.31$ & $8.72 \pm 0.14$ \\
\hline Chapman & Staphylococci & $6.68 \pm 0.15$ & $7.71 \pm 0.15$ & $7.46 \pm 0.26$ \\
\hline $\mathrm{BHI}+$ Tet & S. xylosus donor & $5.87 \pm 0.21$ & $7.11 \pm 0.14$ & $6.87 \pm 0.15$ \\
\hline $\mathrm{BHI}+$ Rif + Fus & S. xylosus recipient & $6.08 \pm 0.16$ & $5.94 \pm 0.12$ & $5.29 \pm 0.16$ \\
\hline BHI + Tet + Rif + Fus & Transconjugant & ND & ND & ND \\
\hline \multirow[t]{2}{*}{ Batch E2 } & $\mathrm{pH}$ & $5.82 \pm 0.05$ & $5.25 \pm 0.08$ & $5.56 \pm 0.16$ \\
\hline & Aw & $0.97 \pm 0.03$ & $0.95 \pm 0.02$ & $0.92 \pm 0.02$ \\
\hline MRS & Lactic acid bacteria & $6.62 \pm 0.10$ & $7.69 \pm 0.23$ & $8.52 \pm 0.15$ \\
\hline Chapman & Staphylococci & $8.32 \pm 0.15$ & $8.72 \pm 0.16$ & $8.03 \pm 0.13$ \\
\hline $\mathrm{BHI}+\mathrm{Tet}$ & S. xylosus donor & $7.92 \pm 0.14$ & $8.24 \pm 0.15$ & $7.60 \pm 0.12$ \\
\hline $\mathrm{BHI}+\mathrm{Rif}+$ Fus & S. xylosus recipient & $8.56 \pm 0.16$ & $8.33 \pm 0.15$ & $7.29 \pm 0.12$ \\
\hline $\mathrm{BHI}+$ Tet + Rif + Fus & Transconjugant & ND & 3 colonies & 1 colony \\
\hline
\end{tabular}

Enumeration expressed in log CFU/g.

Tet, tetracycline; Rif, rifampicin; Fus, fusidic acid; ND, not detected. 
TABLE 2 | Antibiotic susceptibility profiles of S. xylosus strains determined by disk diffusion.

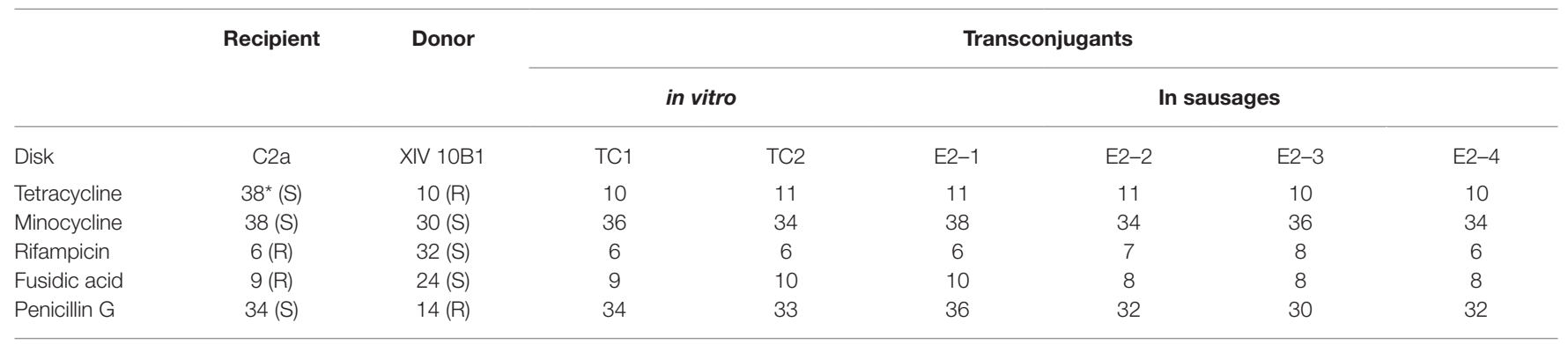

*Diameter expressed in $\mathrm{mm}$.

$S$, sensitive; $R$, resistant.

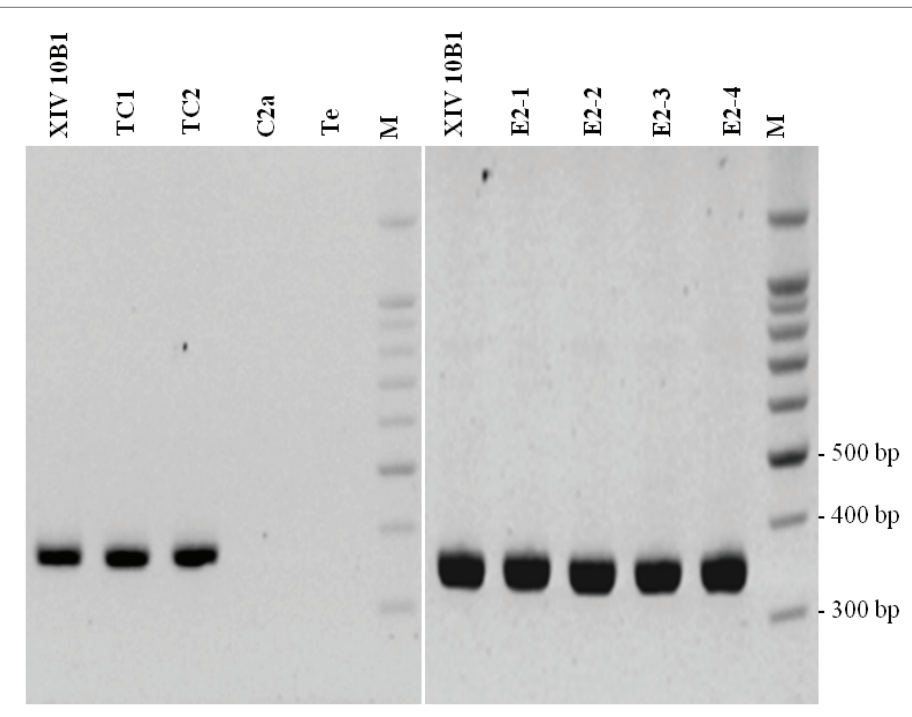

FIGURE 1 | Analysis of tetK PCR (360 bp product). XIV 10B1: donor strain; C2a: recipient strain; TC1 and TC2: transconjugants obtained after in vitro mating; E2-1, E2-2, E2-3: transconjugants isolated from sausages after 6 days of fermentation; E2-4: transconjugant isolated from sausages after 30 days of ripening; Te: negative control; M: DNA 100 bp DNA ladder (Thermo Scientific).

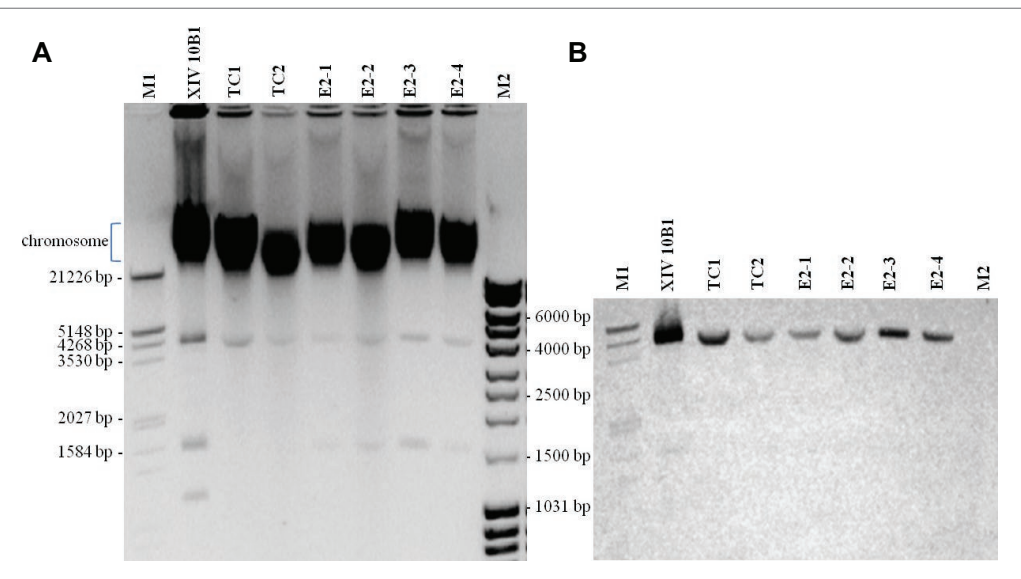

FIGURE 2 | Plasmid analysis from S. xylosus XIV 10B1 and transconjugants. (A) Agarose gel stained with ethidium bromide. (B) Colorimetric detection of Southern blot hybridization with a DIG-labeled probe of the tetK gene. XIV 10B1: donor strain; TC1 and TC2: transconjugants obtained after in vitro mating; E2-1, E2-2, E2-3: transconjugants isolated from sausages after 6 days of fermentation; E2-4: transconjugant isolated from sausages after 30 days of ripening; M1: DNA Molecular Weight Marker III, DIG-labeled (Sigma-Aldrich); M2: MassRuler DNA ladder (Thermo Scientific). 


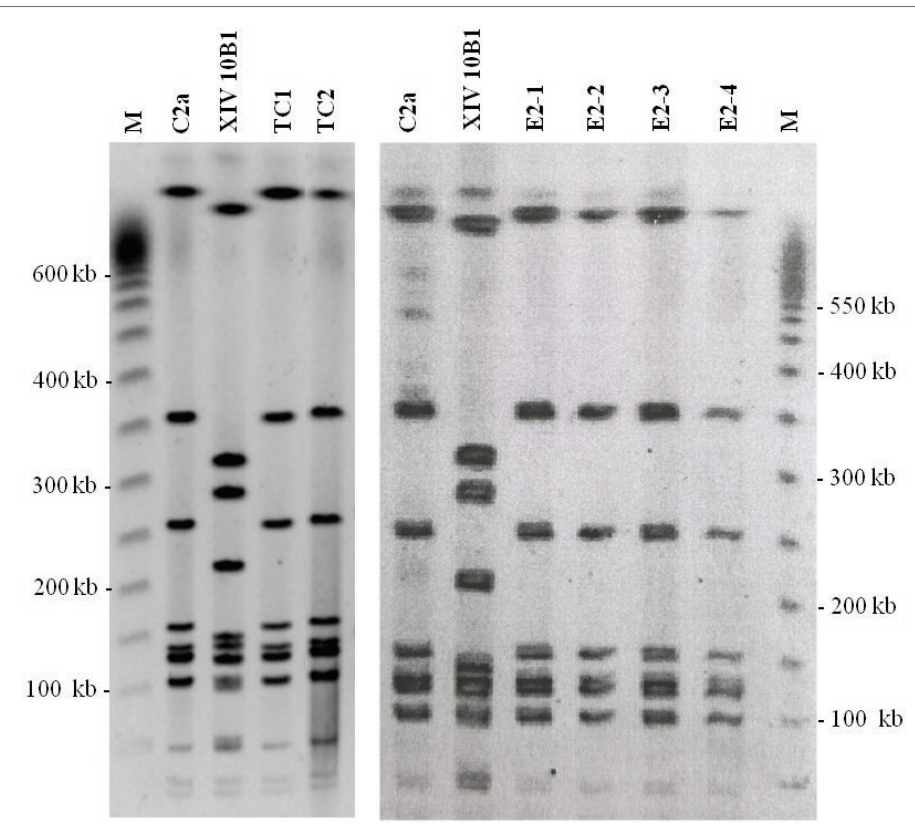

FIGURE 3 I PFGE profiles from S. xylosus strains. C2a: recipient strain; XIV 10B1: donor strain; TC1 and TC2: transconjugants obtained after in vitro mating; E2-1, E2-2, E2-3: transconjugants isolated from sausages after 6 days of fermentation; E2-4: transconjugant isolated from sausages after 30 days of ripening, M: Lambda ladder (Promega).

(TetK), and a plasmid recombination enzyme. It exhibits a high identity (96.5\%) with the S. aureus COL plasmid pT181. Moreover, the amino acid sequence of TetK shows $100 \%$ identity with that of pT181.

Transconjugants, donor, and recipient were subject to PFGE analysis. The donor and recipient produced distinct patterns (Figure 3). The transconjugants displayed the same pattern as the recipient strain.

\section{DISCUSSION}

For several decades, the food chain can be considered the main route of transmission of antibiotic-resistant bacteria between animals and humans (Witte, 1998; Verraes et al., 2013). In the specific case of fermented products, they may be vehicles for large amounts of living bacteria (Mathur and Singh, 2005). In fermented meat products, the most important microorganisms responsible for fermentation are lactic acid bacteria (LAB) and coagulase negative staphylococci (CNS). The antibiotic resistance of $\mathrm{LAB}$ isolated from fermented sausages has been reported in many studies (Fraqueza, 2015, for a review). Recently, the antibiotic resistance in Lactobacillus spp. was assessed by comparing phenotypes and genotypes based on antibioresistance genes (Campedelli et al., 2019). Some antibiotic resistance genes identified in $\mathrm{LAB}$ are transferable and can be potentially transferred between $\mathrm{LAB}$ in vitro or in model rumen and plant environments and fermented milk (Toomey et al., 2009a,b).

However, knowledge about the capacity of LAB to transfer antibiotic resistance in meat matrices is quite limited. During sausage fermentation, the transfer of plasmids carrying antibiotic resistance was demonstrated between strains of L. curvatus (Vogel et al., 1992). A very high frequency of plasmid transfer was also observed between strains of Enterococcus faecalis during the ripening of fermented sausages showing that sausages facilitate close contact between strains and so genetic transfer (Cocconcelli et al., 2003). The spread of antibiotic resistance also concerns meat-associated CNS (Mauriello et al., 2000; Martín et al., 2006; Resch et al., 2008; Even et al., 2010; Marty et al., 2012; Chajęcka-Wierzchowska et al., 2015; Osman et al., 2016). Despite the importance of this group of ubiquitous bacteria, to our knowledge, no study has been made of the transfer of antibiotic resistance in food conditions. Among CNS, S. xylosus has a long history of safe status as found in most naturally fermented meat products and used as starter culture. However, potentially transferable antibiotic resistances, notably erythromycin, penicillin, and tetracycline, have been reported in S. xylosus from fermented meat products (Mauriello et al., 2000; Kastner et al., 2006; Martín et al., 2006; Resch et al., 2008; Even et al., 2010; Marty et al., 2012; ChajęckaWierzchowska et al., 2015).

In the present study, the transfer of the tetracycline resistance gene among $S$. xylosus was studied in vitro or in fermented sausages, since laboratory transfer experiments do not mimic in situ conditions. An estimated conjugation frequency of approximately $1.4 \times 10^{-7}$ per recipient under in situ conditions was calculated, which was higher than that observed in our filter mating conditions. In the only study concerning the transfer of tetracycline resistance in fermented sausages between E. faecalis strains, a very high frequency of $10^{-3}$ per recipient was observed, superior to filter mating (Cocconcelli et al., 2003). In fact, variable rates 
of plasmid transfer, from $10^{-2}$ to $10^{-9}$, are given in the literature. Factors influencing this variation were identified in a meta-analysis based on 28 articles (Hunter et al., 2008). This analysis revealed highly significant associations between transfer frequency and donor and recipient genera. The nature of the transferable genetic element and the membership of the same genus of donor and recipient strains also significantly influenced the transfer (Hunter et al., 2008).

The gene encoding tetracycline resistance is frequently found on small plasmids common among staphylococci (Schwarz and Noble, 1994; Perreten et al., 1998). Small transmissible plasmids carrying the gene tet $K$ encoding efflux protein represent a family of closely related plasmids ranging from 4.4 to $4.7 \mathrm{~kb}$ (Chopra and Roberts, 2001). In our study, the tet $K$ gene of the S. xylosus strain XIV 10B1 isolated from sausage was transferable to a $S$. xylosus recipient and was located on a pT181-like plasmid, the $S$. aureus plasmid pT181 being the prototype from the staphylococcal tetracycline resistance plasmid family (Khan and Novick, 1983). These pT181-like plasmids belonged to the pMV158 superfamily of small mobilizable plasmids (Francia et al., 2004). These non-conjugative mobilizable plasmids are not able to transfer on their own but are able to exploit the mating pore encoded by a helper element, conjugative plasmids or transposons (Francia et al., 2004; Ramsay et al., 2016). In staphylococci, three mechanisms of conjugative mobilization have been elucidated by (1) encoding a mimic sequence of the conjugative plasmid oriT, (2) encoding a distinct relaxase (Mob) compatible with the mating pore and its own related oriT, or (3) carrying a compatible replicative relaxase (Rep) (Ramsay et al., 2016). The helper element by which the S. xylosus XV 10B1 mobilizable plasmid is transferred between S. xylosus strains remains to be identified.

Metagenomic analyses have been applied to monitor antibiotic resistance genes in two dairy products microbiota. One screened antibiotic resistance genes in mozzarella cheese (Devirgiliis et al., 2014) and the other in raw milk and blue veined cheese (Flórez et al., 2017). The latter study targeted on tetracycline resistance genes coding for ribosomal protection proteins (tetM, tetS) and efflux pumps (tet $A$, tet $L)$; tet $A$ was found in plasmids from Gram-negative bacteria, while the three others were from lactic acid bacteria (Flórez et al., 2017). However, the dairy microbiota "resistome" and even more

\section{REFERENCES}

Anisimova, E., and Yarullina, D. (2018). Characterization of erythromycin and tetracycline resistance in Lactobacillus fermentum strains. Int. J. Microbiol. 2018:3912326. doi: 10.1155/2018/3912326

Bhargava, K., and Zhang, Y. (2012). Multidrug-resistant coagulase-negative Staphylococci in food animals. J. Appl. Microbiol. 113, 1027-1036. doi: 10.1111/j.1365-2672.2012.05410.x

Campedelli, I., Mathur, H., Saletti, E., Clarke, S., Rea, M. C., Torriani, S., et al. (2019). Genus-wide assessment of antibiotic resistance in Lactobacillus spp. Appl. Environ. Microbiol. 85:e01738-18. doi: 10.1128/ AEM.01738-18

CA-SFM/EUCAST. (2017). Comité de l'Antibiogramme de la Société Française de Microbiologie. (Paris, France: Société Française de Microbiologie Ed), 1-127. http://www.sfm-microbiologie.org/UserFiles/files/casfm/ the meat microbiota "resistome" have yet to be explored. The antimicrobial resistance of these food bacteria could be transmitted to gut microbiota and constitute a threat to human health (Devirgiliis et al., 2011; Schjørring and Krogfelt, 2011; Forslund et al., 2014).

The transfer of antimicrobial resistance between starters and foodborne pathogens has to be further investigated, to our knowledge, transfer occurred in vitro between LAB and Listeria but not with other pathogens and not in cheese matrix (Gevers et al., 2003; Toomey et al., 2009b). Similar studies should be carried out to assess if fermented sausages can constitute an environment for gene exchange between starters and pathogenic bacteria, it would be of utmost importance between $S$. xylosus and S. aureus or other CNS as plasmids of the pT181 family are transmissible and could disseminated within fermented foods. Thus, the selection of starter cultures such as S. xylosus should consider antibiotic resistances and their potential transfer to other strains. All these studies have pushed the starter industry to consider this risk factor and therefore comply with the AFSSA safety recommendations and the European QPS approach.

\section{AUTHOR CONTRIBUTIONS}

SL and RT conceived the study and wrote the manuscript. SL, SC, and RT designed the experiments. SL and SC performed the laboratory experiments. SL, SC, and RT analyzed the data, contributed to preparing the final version of the manuscript, and approved the final manuscript.

\section{FUNDING}

A part of this work was financially supported by the French National Research Agency (ANR) project "SCN/BEER" ANR-05-PNRA-020.

\section{ACKNOWLEDGMENTS}

The authors are grateful to David Marsh for correcting our English.

Chajęcka-Wierzchowska, W., Zadernowska, A., Nalepa, B., Sierpińska, M., and Łaniewska-Trokenheim, Ł. (2015). Coagulase-negative staphylococci (CoNS) isolated from ready-to-eat food of animal origin-phenotypic and genotypic antibiotic resistance. Food Microbiol. 46, 222-226. doi: 10.1016/j.fm.2014.08.001

Chon, J. W., Jung, H. I., Kuk, M., Lim, J. S., Seo, K. H., and Kim, S. K. (2016). Microbiological evaluation of pork and chicken by-products in South Korea. J. Food Prot. 79, 715-722. doi: 10.4315/0362-028X.JFP-15-395

Chopra, I., and Roberts, M. (2001). Tetracycline antibiotics: mode of action, applications, molecular biology, and epidemiology of bacterial resistance. Microbiol. Mol. Biol. Rev. 65, 232-260. doi: 10.1128/MMBR.65.2.232-260.2001

Cocconcelli, P. S., Cattivelli, D., and Gazzola, S. (2003). Gene transfer of vancomycin and tetracycline resistance among E. faecalis during cheese and sausage fermentations. Int. J. Food Microbiol. 88, 315-323. doi: 10.1016/ S0168-1605(03)00194-6

Corbière Morot-Bizot, S., Talon, R., and Leroy, S. (2004). Development of a multiplex PCR for the identification of Staphylococcus genus and four 
staphylococcal species isolated from food. J. Appl. Microbiol. 97, 1087-1094. doi: $10.1111 /$ j.1365-2672.2004.02399.x

Coton, E., Desmonts, M. H., Leroy, S., Coton, M., Jamet, E., Christieans, S., et al. (2010). Biodiversity of coagulase-negative staphylococci in French cheeses, dry fermented sausages, processing environments and clinical samples. Int. J. Food Microbiol. 137, 221-229. doi: 10.1016/j.ijfoodmicro.2009.11.023

Devirgiliis, C., Barile, S., and Perozzi, G. (2011). Antibiotic resistance determinants in the interplay between food and gut microbiota. Genes Nutr. 6, 275-284. doi: 10.1007/s12263-011-0226-x

Devirgiliis, C., Zinno, P., Stirpe, M., Barile, S., and Perozzi, G. (2014). Functional screening of antibiotic resistance genes from a representative metagenomic library of food fermenting microbiota. Biomed. Res. Int. 2014:290967. doi: $10.1155 / 2014 / 290967$

Ed-Dra, A., Filali, F. R., Bouymajane, A., Benhallam, F., El Allaoui, A., Chaiba, A., et al. (2018). Antibiotic susceptibility of $S$. aureus isolated from sausages in Meknes, Morocco. Vet. World 11, 1459-1465. doi: 10.14202/vetworld.2018.1459-1465

Even, S., Leroy, S., Charlier, C., Ben Zakour, N., Chacornac, J. P., Lebert, I., et al. (2010). Low occurrence of safety hazards in coagulase negative staphylococci isolated from fermented foodstuffs. Int. J. Food Microbiol. 139, 87-95. doi: 10.1016/j.ijfoodmicro.2010.02.019

Flórez, A. B., Vázquez, L., and Mayo, B. (2017). A Functional metagenomic analysis of tetracycline resistance in cheese bacteria. Front. Microbiol. 8:907. doi:10.3389/fmicb.2017.00907

Forslund, K., Sunagawa, S., Coelho, L. P., and Bork, P. (2014). Metagenomic insights into the human gut resistome and the forces that shape it. BioEssays 36, 316-329. doi: 10.1002/bies.201300143

Francia, M. V., Varsaki, A., Garcillán-Barcia, M. P., Latorre, A., Drainas, C., and de la Cruz, F. (2004). A classification scheme for mobilization regions of bacterial plasmids. FEMS Microbiol. Rev. 28, 79-100. doi: 10.1016/j. femsre.2003.09.001

Fraqueza, M. J. (2015). Antibiotic resistance of lactic acid bacteria isolated from dry-fermented sausages. Int. J. Food Microbiol. 212, 76-88. doi: 10.1016/j. ijfoodmicro.2015.04.035

Gevers, D., Huys, G., and Swings, J. (2003). In vitro conjugal transfer of tetracycline resistance from Lactobacillus isolates to other Gram-positive bacteria. FEMS Microbiol. Lett. 225, 125-130. doi: 10.1016/S0378-1097(03)00505-6

Götz, F., Zabielski, J., Philipson, L., and Lindberg, M. (1983). DNA homology between the arsenate resistance plasmid pSX267 from S. xylosus and the penicillinase plasmid pI258 from S. aureus. Plasmid 9, 126-137. doi: 10.1016/0147-619X(83)90015-X

Greppi, A., Ferrocino, I., La Storia, A., Rantsiou, K., Ercolini, D., and Cocolin, L. (2015). Monitoring of the microbiota of fermented sausages by culture independent rRNA-based approaches. Int. J. Food Microbiol. 212, 67-75. doi: 10.1016/j. ijfoodmicro.2015.01.016

Huang, X., and Madan, A. (1999). CAP3: A DNA sequence assembly program. Genome Res. 9, 868-877. doi: 10.1101/gr.9.9.868

Hunter, P. R., Wilkinson, D. C., Catling, L. A., and Barker, G. C. (2008). Meta-analysis of experimental data concerning antimicrobial resistance gene transfer rates during conjugation. Appl. Environ. Microbiol. 74, 6085-6090. doi: 10.1128/AEM.01036-08

Kastner, S., Perreten, V., Bleulera, H., Hugenschmidt, G., Lacroix, C., and Meile, L. (2006). Antibiotic susceptibility patterns and resistance genes of starter cultures and probiotic bacteria used in food. Syst. Appl. Microbiol. 29, 145-155. doi: 10.1016/j.syapm.2005.07.009

Khan, S. A., and Novick, R. P. (1983). Complete nucleotide sequence of pT181, a tetracycline-resistance plasmid from S. aureus. Plasmid 10, 251-259. doi: 10.1016/0147-619X(83)90039-2

Leroy, S., Giammarinaro, P., Chacornac, J. P., Lebert, I., and Talon, R. (2010). Biodiversity of indigenous staphylococci of naturally fermented dry sausages and manufacturing environments of small-scale processing units. Food Microbiol. 27, 249-301. doi: 10.1016/j.fm.2009.11.005

Li, L., Ye, L., Zhang, S., and Meng, H. (2016). Isolation and identification of aerobic bacteria carrying tetracycline and sulfonamide resistance genes obtained from meat processing plant. J. Food Sci. 81, M1480-M1484. doi: $10.1111 / 1750-3841.13318$

Lüdin, P., Roetschi, A., Wüthrich, D., Bruggmann, R., Berthoud, H., and Shani, N. (2018). Update on tetracycline susceptibility of Pediococcus acidilactici based on strains isolated from swiss cheese and whey. J. Food Prot. 81, 1582-1589. doi: 10.4315/0362-028X.JFP-18-160
Malik, S., Peng, H., and Barton, M. D. (2005). Antibiotic resistance in staphylococci associated with cats and dogs. J. Appl. Microbiol. 99, 1283-1293. doi: 10.1111/j. 1365-2672.2005.02699.x

Marmur, J. (1961). A procedure for the isolation of deoxyribonucleic acid from microorganism. J. Mol. Biol. 3, 208-218. doi: 10.1016/S0022-2836(61)80047-8

Martín, B., Garriga, M., Hugas, M., Bover-Cid, S., Veciana-Nogues, M. T., and Aymerich, T. (2006). Molecular, technological and safety characterization of Gram-positive catalase-positive cocci from slightly fermented sausages. Int. J. Food Microbiol. 107, 148-158. doi: 10.1016/j.ijfoodmicro.2005.08.024

Marty, E., Bodenmann, C., Buchs, J., Hadorn, R., Eugster-Meier, E., Lacroix, C., et al. (2012). Prevalence of antibiotic resistance in coagulase-negative staphylococci from spontaneously fermented meat products and safety assessment for new starters. Int. J. Food Microbiol. 159, 74-83. doi: 10.1016/j.ijfoodmicro.2012.07.025

Mathur, S., and Singh, R. (2005). Antibiotic resistance in food lactic acid bacteria -a review. Int. J. Food Microbiol. 105, 281-295. doi: 10.1016/j. ijfoodmicro.2005.03.008

Mauriello, G., Moschetti, G., Villani, F., Blaiotta, G., and Coppola, S. (2000). Antibiotic resistance of coagulase-negative staphylococci isolated from artisanal Naples-type salami. Int. J. Food Sci. Nutr. 51, 19-24.

Morot-Bizot, S., Talon, R., and Leroy-Setrin, S. (2003). Development of specific PCR primers for a rapid and accurate identification of S. xylosus, a species used in food fermentation. J. Microbiol. Methods 55, 279-286. doi: 10.1016/ S0167-7012(03)00159-3

Osman, K., Badr, J., Al-Maary, K. S., Moussa, I. M. I., Hessain, A. M., Girah, Z. M. S. A., Abo-shama, U. H., Orabi, A., and Saad, A. (2016). Prevalence of the antibiotic resistance genes in coagulase-positive-and negativeStaphylococcus in chicken meat retailed to consumers. Front. Microbiol. 7:1846. doi: $10.3389 /$ fmicb.2016.01846

Perreten, V., Giampà, N., Schuler-Schmid, U., and Teuber, M. (1998). Antibiotic resistance genes in coagulase-negative staphylococci isolated from food. Syst. Appl. Microbiol. 21, 113-120. doi: 10.1016/S0723-2020(98)80014-3

Ramsay, J. P., Kwong, S. M., Murphy, R. J. T., Yui Eto, K., Price, K. J., Nguyen, Q. T., et al. (2016). An updated view of plasmid conjugation and mobilization in Staphylococcus. Mob. Genet. Elem. 6:e1208317. doi: 10.1080/2159256X.2016.1208317

Ratsimba, A., Leroy, S., Chacornac, J. P., Rakoto, D., Arnaud, E., Jeannoda, V., et al. (2017). Staphylococcal ecosystem of kitoza, a traditional Malagasy meat product. Int. J. Food Microbiol. 246, 20-24. doi: 10.1016/j.ijfoodmicro.2017.02.001

Resch, M., Nagel, V., and Hertel, C. (2008). Antibiotic resistance of coagulase-negative staphylococci associated with food and used in starter cultures. Int. J. Food Microbiol. 127, 99-104. doi: 10.1016/j.ijfoodmicro.2008.06.013

Roberts, M. C. (1996). Tetracycline resistant determinants: mechanisms of action, regulation of expression, genetic mobility and distribution. FEMS Microbiol. Rev. 19, 1-24. doi: 10.1111/j.1574-6976.1996.tb00251.x

Sánchez Mainar, M., Stavropoulou, D. A., and Leroy, F. (2017). Exploring the metabolic heterogeneity of coagulase-negative staphylococci to improve the quality and safety of fermented meats: a review. Int. J. Food Microbiol. 247, 24-37. doi: 10.1016/j.ijfoodmicro.2016.05.021

Schjørring, S., and Krogfelt, K. A. (2011). Assessment of bacterial antibiotic resistance transfer in the gut. Int. J. Microbiol. 2011:312956. doi: $10.1155 / 2011 / 312956$

Schwarz, S., and Noble, W. C. (1994). Tetracycline resistance in staphylococci from the skin of pigs. J. Appl. Bacteriol. 78, 320-326.

Schwarz, S., Roberts, M. C., Werckenthin, C., Pang, Y., and Lange, C. (1998). Tetracycline resistance in Staphylococcus spp. from domestic and pet animals. Vet. Microbiol. 63, 217-228. doi: 10.1016/S0378-1135(98)00234-X

Simeoni, D., Rizzottia, L., Cocconcelli, P., Gazzola, S., Dellaglioa, F., and Torriani, S. (2008). Antibiotic resistance genes and identification of staphylococci collected from the production chain of swine meat commodities. Food Microbiol. 25, 196-201. doi: 10.1016/j.fm.2007.09.004

Strommenger, B., Kettlitz, C., Werner, G., and Witte, W. (2003). Multiplex PCR assay for simultaneous detection of nine clinically relevant antibiotic resistance genes in S. aureus. J. Clin. Microbiol. 41, 4089-4094. doi: 10.1128/ JCM.41.9.4089-4094.2003

Talon, R., and Leroy, S. (2011). Diversity and safety hasards of bacteria involved in meat fermentations. Meat Sci. 89, 303-309. doi: 10.1016/j.meatsci.2011.04.029

Thaker, M., Spanogiannopoulos, P., and Wright, G. D. (2010). The tetracycline resistome. Cell. Mol. Life Sci. 67, 419-431. doi: 10.1007/s00018-009-0172-6

Toomey, N., Monaghan, A., Fanning, S., and Bolton, D. (2009a). Transfer of antibiotic resistance marker genes between lactic acid bacteria in model 
rumen and plant environments. Appl. Environ. Microbiol. 75, 3146-3152. doi: 10.1128/AEM.02471-08

Toomey, N., Monaghan, A., Fanning, S., and Bolton, D. (2009b). Assessment of antimicrobial resistance transfer between lactic acid bacteria and potential foodborne pathogens using in vitro methods and mating in food matrix. Foodborne Pathog. Dis. 6, 925-933. doi: 10.1089/fpd.2009.0278

van Hoek, A. H. A. M., Mevius, D., Guerra, B., Mullany, P., Roberts, A. P., and Aarts, H. J. M. (2011). Acquired antibiotic resistance genes: an overview. Front. Microbiol. 2:203. doi: 10.3389/fmicb.2011.00203

Verraes, C., van Boxstael, S., van Meervenne, E., van Coillie, E., Butaye, P., Catry, B., et al. (2013). Antimicrobial resistance in the food chain: a review. Int. J. Environ. Res. Public Health 10, 2643-2669. doi: 10.3390/ ijerph10072643

Vogel, R. F., Becke-Schmid, M., Entgens, P., and Hammes, W. P. (1992). Plasmid transfer and segregation in L. curvatus LTH 1432 in vitro and during sausage fermentation. Syst. Appl. Microbiol. 15, 129-136. doi: 10.1016/S0723-2020(11)80149-9
Witte, W. (1998). Medical consequences of antibiotic use in agriculture. Science 279, 996-997. doi: 10.1126/science.279.5353.996

Wu, S., Huang, J., Wu, Q., Zhang, J., Zhang, F., Yang, X., et al. (2018). S. aureus isolated from retail meat and meat products in china: incidence, antibiotic resistance and genetic diversity. Front. Microbiol. 9:2767. doi: 10.3389/fmicb.2018.02767

Conflict of Interest Statement: The authors declare that the research was conducted in the absence of any commercial or financial relationships that could be construed as a potential conflict of interest.

Copyright (C) 2019 Leroy, Christieans and Talon. This is an open-access article distributed under the terms of the Creative Commons Attribution License (CC BY). The use, distribution or reproduction in other forums is permitted, provided the original author(s) and the copyright owner(s) are credited and that the original publication in this journal is cited, in accordance with accepted academic practice. No use, distribution or reproduction is permitted which does not comply with these terms. 